\title{
TITLE:
}

\section{Cultural grounding of regret: regret in self and interpersonal contexts.}

$\operatorname{AUTHOR}(S)$ :

Komiya, Asuka; Miyamoto, Yuri; Watabe, Motoki; Kusumi, Takashi

\section{CITATION:}

Komiya, Asuka ...[et al]. Cultural grounding of regret: regret in self and interpersonal contexts.. Cognition \& Emotion 2010, 25(6): 1121-1130

\section{ISSUE DATE:}

2010-11-10

URL:

http://hdl.handle.net/2433/197226

\section{RIGHT:}

This is an Accepted Manuscript of an article published by Taylor \& Francis in Cognition \& Emotion on 2010, available online:

http://www.tandfonline.com/10.1080/02699931.2010.51696; This is not the published version. Please cite only the published version.; この論文は出版社版でありません。引用 の際には出版社版をご確認ご利用ください。 
Brief Report [3973 words]

Running Head: CULTURE AND REGRET

Cultural Grounding of Regret: Regret in Self and Interpersonal Contexts

Asuka Komiya

Kyoto University

\author{
Yuri Miyamoto \\ University of Wisconsin-Madison
}

Motoki Watabe

Waseda University

Takashi Kusumi

Kyoto University

Correspondence should be addressed to:

Asuka Komiya, Department of Education, Kyoto University, Yoshida-honmachi, Sakyo-ku, Kyoto 606-8501; FAX:+81-75-753-3067; e-mail: komiya@t02.mbox.media.kyoto-u.ac.jp

Keywords: regret, cultural differences, action and inaction 


\begin{abstract}
The purpose of this study was to explore cultural similarities and differences in regret, focusing on distinctions between interpersonal and self situations, and between action and inaction regrets. Japanese and American undergraduates were asked to describe regrets experienced in interpersonal and self situations. We found that both situational and cultural contexts influenced the likelihood of regretting inactions over actions. Participants were more likely to recall inaction regrets in self situations than in interpersonal situations, and that the likelihood of recalling inaction regrets was more pronounced for Americans than Japanese. Furthermore, we examined the intensity of the regret. Whereas American students experienced regret as intense as that of Japanese students in self situations, Japanese students experienced regret more strongly than American students in interpersonal situations. Detailed content analysis also showed that individuals experienced regret in ways consistent with cultural values. The situational and cultural grounding of regret is discussed.
\end{abstract}


Culture and Regret 3

\section{Acknowledgements}

This study was supported by a research fellowship from the Japan Society for the Promotion of

Science. We thank Satoko Yokoo for coding and Brooke Wilken, Amanda Eggen, and Yukiko

Uchida for helpful comments on the manuscript. 
Regret is ubiquitous in daily life. People feel regret in various situations, ranging from when they do not try as hard as they should in school, to when they make insensitive remarks that cause others' hurt feelings. Although a growing literature has demonstrated various contextual factors (e.g., Berndsen, van der Pligt, Doosje, \& Manstead, 2004; Kahneman \& Tversky, 1982) and individual differences (e.g., Pierro, Leder, Mannetti, Higgins, Kruglanski, \& Antonio, 2008) that can influence regret, little is known about cultural grounding of regret. The present study examined cultural similarities and differences in regret and explored relationships among cultures, situations, and cognitive processes.

\section{Culture and Regret: Self and Interpersonal Situations}

Regret is a negative emotion experienced upon imagining that the present situation would be better if different decisions had been made (Zeelenberg \& Pieters, 2006). It is classically elicited by a counterfactual comparison between the outcome of a choice (i.e., reality) and the better outcome of previously rejected alternatives (i.e., what might have been; Kahneman \& Tversky, 1982). Since regret embodies a painful lesson that things would have been better with different choices, researchers have suggested that it functions to guide more appropriate behavior (e.g., Gilovich \& Medvec, 1995; Zeelenberg \& Pieters, 2006). However, it is still unknown whether regret functions differently depending on social and cultural contexts.

Recent studies have suggested that models of agency differ across cultures (Markus \& Kitayama, 2004). In American middle-class cultural contexts, actions are considered to originate 
from an autonomous self. According to this disjoint model of agency, the individual's own preferences and goals, independent of social influences, are the primary source of action. In such cultural contexts, people are assumed to feel agentic and committed to their actions when they do not involve others. For example, European American children display more intrinsic motivation for an activity which they chose for themselves than for one which was chosen for them by others (Iyengar \& Lepper, 1999). In contrast, in East Asian cultural contexts, actions are driven by a motivation to maintain one's position in relationships with others. According to this conjoint model of agency, agency arises from acting to meet interpersonal expectations (Miller, 2004). In these cultural contexts, people are assumed to feel agentic and committed to their actions when they meaningfully involve others and their expectations. In fact, Asian children display more intrinsic motivation for an activity which their mothers chose for them than for one which they chose for themselves (Iyengar \& Lepper, 1999).

Although a disjoint model of agency has traditionally been considered to be the normative model of agency, both disjoint and conjoint models of agency involve a sense of freedom, commitment, and responsibility_core concepts associated with agency (Ryan, 1991). This suggests that people feel agentic across cultures. However, the two models of agency differ in when people are expected to feel agentic. According to the disjoint model of agency, a sense of agency, commitment, and responsibility should be experienced when actions are performed without the involvement of others. In contrast, according to the conjoint model of agency, a sense 
of agency, commitment, and responsibility should be experienced when actions involve others.

Supporting this proposition, previous studies showed that Americans are more likely than Japanese to engage in dissonance reduction when a choice does not involve others, whereas Japanese are more likely than Americans to engage in dissonance reduction when making a choice while thinking about others explicitly or implicitly (Heine \& Lehman, 1997; Kitayama, Snibbe, Markus, \& Suzuki, 2004). Because dissonance reduction requires a sense of responsibility and agency (Cooper \& Fazio, 1984), these findings suggest that there are cultural differences in when people feel responsibility for their choice. Given that the sense of responsibility and agency is a core feature of regret (e.g., van Dijk \& Zeelenberg, 2002), this should also have implications for the context in which strong regret is experienced.

The first objective of this study was to investigate cultural characteristics of regret by comparing interpersonal and self situations. Based on prior studies, we examined whether or not cultural differences in the intensity of regret depend on the nature of situations. We defined a self situation as one where only the person experiencing the regret is involved. For example, not studying enough or wasting money by shopping would be potential causes of regret in a self situation. On the other hand, we defined an interpersonal situation as one involving others. Note that, in an interpersonal situation, others could be involved not only directly, such as hurting friends, but also indirectly, such as not spending enough time with one's family. We predicted that whereas Americans would feel more regret than Japanese in self situations, Japanese would feel 
more regret than Americans in interpersonal situations.

\section{Culture and the Cognitive Process of Regret: Action-Inaction}

Cultural comparison studies of regret (Chen, Chiu, Roese, Tam, \& Lau, 2006; Gilovich, Wang, Regan, \& Nishina, 2003; Zou, Tam, Morris, Lee, Lau, \& Chiu, 2009) mainly focus on action and inaction — the types of regret which have traditionally been investigated (e.g., Kahneman \& Tversky, 1982). Regret for actions refers to what people have actually done but wish that they had not done (e.g., George trades stock in Company A for stock in Company B), and regret for inactions refers to what people have not actually done but wish that they had done (e.g., Paul considers buying stock in Company B but keeps his stock in Company A). Previous research has shown that when Americans were asked to recall their biggest regret, they were more likely to report regrets for inactions than for actions (Gilovich \& Medvec, 1994).

The second objective of this study was to examine whether the action-inaction tendencies might depend on self and interpersonal situations, as well as on the cultural contexts. Previous studies conducted in Western cultures where independent agency is emphasized have mainly focused on regret experienced in self situations. For example, the most frequently mentioned regrets in Gilovich and Medvec (1995) were “missed educational opportunities” and "failure to seize the moment”. It is possible that when people look back at themselves as individuals, independent from any interpersonal contexts, the issue of attaining accomplishments and fulfilling their own hopes and desires may become salient, leading them to regret failure to act to advance 
themselves. On the other hand, when people look back at themselves in relations to others, the issue of securing social harmony and being responsible may become more salient, leading them to regret actions that actively obstruct social relations.

Supporting this possibility, Zeelenberg, van der Pligt, and Manstead (1998) reported that Dutch were more motivated to apologize after a regrettable action than after a regrettable inaction when issues of interpersonal harm were underscored. Furthermore, Feeney, Gardiner, Johnston, Jones, and Mcevoy (2005) showed that whereas participants regretted inaction more than action in a personal domain, they regretted action as much as inaction in an interpersonal domain. It is thus possible that the tendency to regret inactions over actions might be confined to self situations and might be attenuated in interpersonal situations.

In addition, we also sought to examine cultural differences in the tendency to regret inactions over actions in self and interpersonal situations. Previous studies have found that individuals with interdependent self-construals tend to focus on preventing negative outcomes rather than promoting positive outcomes (Lee, Aaker, \& Gardner, 2000). Because prevention-focused self-regulation has been linked to the tendency to regret actions more strongly than inactions (e.g., Roese, Hur, \& Pennington, 1999), East Asians may be more likely than Americans to regret actions. In fact, Zou et al. (2009) recently showed that Chinese are more likely than Americans to regret actions, and regulatory focus mediates the cultural differences in the tendency to regret actions. 
Despite these general cultural differences, however, both Chinese and Americans were more likely to regret inactions than to regret actions in all of the previous cross-cultural studies (Chen et al., 2006; Gilovich et al., 2003; Zou et al., 2009). These findings might be partly due to the fact that researchers typically focused on self situations (Gilovich et al., 2003). Although Chen et al. (2006) compared regrets across various domains (e.g., general, romance), they did not manipulate or measure whether the others are involved or only the self is involved in the experience of regret. In the present study, we focused on the difference between self and interpersonal situations, and examined whether the tendency to regret inactions over actions may disappear or even be reversed for East Asians in interpersonal situations where the risk of disturbing social relationships is more salient.

To summarize, we tested two hypotheses about action and inaction regrets: the tendency to regret inactions over actions would be stronger (i) in self situations than in interpersonal situations, and (ii) among Americans than among Japanese. Specifically, based on the previous findings, we predicted that, in self situations, participants would be more likely to recall regret about inactions than about actions. On the other hand, because of the heightened risk of disturbing social relationships in interpersonal situations, we predicted that participants would be more likely to recall regret about actions in interpersonal situations than in self situations. Moreover, the tendency to recall inactions over actions may be weaker among Japanese participants than among American participants. As a joint result of these situational and cultural effects, we also explored 
whether Japanese individuals may regret actions over inactions in interpersonal situations—a phenomenon that has not been observed in previous studies.

In this study, we used a list-up method employed by previous studies (Chen et al., 2006;

Gilovich et al., 2003). Japanese and American undergraduates were asked to recall their strongest short-term and long-term regrets ${ }^{1}$ for both interpersonal and self situations, and rate the intensity of regret in each situation. To investigate the type of regret, trained coders categorized the responses in terms of inaction or action. We analyzed two aspects of regret: intensity and proportion of action to inaction. Furthermore, we explored cultural similarities and differences in the detailed content of regret.

Method

\section{Participants}

Forty European American undergraduates at the University of Wisconsin-Madison (17 women) and 39 Japanese undergraduates at Kyoto University (21 women) were recruited from the subject pool at respective institution. Whereas American students received course credits, Japanese students were given 500-yen book coupons (equivalent to \$5 US) in exchange for their participation. $^{2}$

Procedure

Both American and Japanese participants filled out a questionnaire in small groups (1-5 individuals). In this questionnaire, participants first read definitions for interpersonal situations 
(i.e., those involving others) and self situations (i.e., those involving only the self), and were then asked to review both their lives (i.e., long-term) and the last week (i.e., short-term) and briefly describe the event which they most regretted in each situation. Subsequently, participants completed the following sentence for each event: "If only ..., then...” (i.e., counterfactual). They next rated the extent to which they regretted the events using an 11-point scale ranging from 0 (not at all) to 10 (very much). Finally, participants provided demographic information.

The questionnaire was translated by two Japanese-English bilinguals using the back translation method. The order of the regret questionnaires was counter-balanced; we prepared four versions of the questionnaire, varying the order of temporal perspectives and situation types. The order did not affect the results.

\section{Coding}

Three judges coded all situations and counterfactuals generated by the participants. Each response was coded by a native of the culture and by a bilingual coder, both of whom were blind to the hypotheses. Discrepancies were resolved by discussions among coders.

Coding was conducted in three phases. First, as a manipulation check, the judges classified responses in self situations into "reference to others" or "nonreference", depending on whether the sentence contained a noun indicating the presence of specific others (e.g., a family member or a classmate). Regrets including group nouns, such as club and class, were coded as nonreference because the involvement of others is ambiguous. Levels of inter-coder reliability were acceptable 
(Cohen’s kappa; 0.96 and 0.98, for Japanese and for American events, respectively).

In the second phase of coding, judges classified all responses into action (e.g., wasting time, hurting a friend) or inaction (e.g., not studying enough, not helping a friend). Two events were not classified because they were too ambiguous (e.g., "I wish I could have done better on my exam.”). Finally, we conducted more detailed coding of the content, including four coding schemas for inaction and action in interpersonal and self situations. The coding schema is shown in Table1. Levels of inter-coder reliability (Cohen’s kappa) were acceptable (range: 0.65-0.86, M: 0.76).

Results

\section{Manipulation Check}

Seven Japanese respondents and fourteen American respondents wrote a regret involving others in self situations. Some participants might have placed these regrets in self situations because the regrets did not involve direct interactions with others (e.g., not telling a girl you love her). In accordance with our distinction between self and interpersonal situations, we excluded these situations from the analysis. The general pattern of results, however, was the same, irrespective of whether these data were included.

Intensity of Regret

A 2 (Culture: Japan or U.S.) x 2 (Time: long- or short-term) x 2 (Situation: self or interpersonal) mixed ANOVA was conducted. ${ }^{3}$ First, not surprisingly, the main effect of time was significant, $F(1,45)=12.69, M S E=5.21, p<.001$, implying that participants felt regret more 
strongly over the lifespan than over the last week. This main effect was marginally qualified by time, $F(1,45)=3.50, M S E=1.83, p=.07$, suggesting that the effect of time was stronger in interpersonal situations, $F(1,45)=14.91, M S E=3.81, p<.01$, than in self situations, $F(1,45)=$ 4.87, MSE $=3.23, p<.05$.

Most importantly, as expected, the Culture $\mathrm{x}$ Situation interaction was significant, $F(1,45)=$ 5.46, MSE $=2.97, p<.05$. The follow up analysis revealed that Japanese respondents felt regret more strongly than American respondents in interpersonal situations, $F(1,45)=7.92, M S E=4.38$, $p<.01$. However, contrary to the hypothesis, Japanese respondents felt as much regret as American respondents in self situations, $F(1,45)=0.007, M S E=5.62, p=.94$. This interaction was not qualified by time. No other interactions or main effects were significant, $p s>.11$ (see Figure 1).

The Proportions of Action and Inaction

To examine the effect of time perspective, we first conducted Chi-square tests on the coded data in each situation and each culture, with Time (long-term vs. short-term) as an independent variable. Surprisingly, Time did not significantly affect the proportion of action or inaction regrets, $\theta \mathrm{s}<.10$, unlike previous studies (Gilovich \& Medvec, 1995).

To test our hypotheses, we performed Chi-square tests on the coded data, collapsing the time factor. The frequencies of actions and inactions in each culture and situation are presented in Table 1. First, supporting our hypothesis, both Japanese and American participants produced more action 
regrets in interpersonal situations than in self situations, $\chi^{2}(1)=20.82, p<.001, \theta=.39$, for Japanese, and $\chi^{2}(1)=12.25, p<.001, \theta=.30$, for Americans. Second, Japanese respondents were more likely to report actions than Americans in both interpersonal, $\chi^{2}(1)=3.87, p<.05, \theta=.16$, and self situations, $\chi^{2}(1)=8.59, p<.01, \quad \theta=.27$, as we expected.

Finally, to examine whether participants were more likely to produce actions or inactions in each type of situation, we performed binominal tests separately for Americans and Japanese, and for self and interpersonal situations. In self situations, consistent with previous findings, both Japanese (62.3\% vs. 37.3\%; $z=-1.92, p=.07)$ and American (85.7\% vs. $14.3 \% ; z=-5.67, p$ $<$.001) respondents regretted inactions more frequently than actions, though the trend was marginal for Japanese. In interpersonal situations, however, Japanese respondents produced more regrets about actions than inactions (68.1\% vs. 31.9\%; $z=3.06, p<.001)$, whereas Americans reported as many regrets about actions as inactions (52.1\% vs. $47.9 \%$; $z=0.35$, n.s.)

The Content of Regret in the United States and Japan

Additionally, we performed more detailed coding to examine the content of regret. The coding schema and the frequency of types of regret are presented in Table 1.

Insert Table1 about here

Interestingly, in self situations, missing opportunities or not working enough was the most common regret experienced by both American and Japanese students. However, American students reported more frequent regret for missing opportunities than did Japanese, $\chi^{2}(1)=8.77$, $p<.01, \theta=.27$, whereas Japanese more frequently mentioned actions related to wasting time, $x$ 
${ }^{2}(1)=6.12, p<.05, \theta=.22$, or unwise decisions than Americans, $\chi^{2}(1)=3.12, p=.08, \theta=.16$, which may reflect East Asians' motivation to learn from past mistakes and improve the self (Heine, Lehman, Markus, \& Kitayama, 1999).

On the other hand, in interpersonal situations, hurting or annoying friends or family was the most common regret experienced in both the U.S. and Japan, though twice as many Japanese reported such regret, $\chi^{2}(1)=4.83, p<.05, \theta=.18$. Americans reported experiencing more regret than Japanese respondents about poor group performances that were attributable to their own behaviors, irrespective of whether these outcomes related to inactions, $\chi^{2}(1)=3.68, p=.06, \theta$ $=.16$, or actions, $\chi^{2}(1)=2.72, p<.10, \theta=.14$. Poor group performance has negative consequences not only for others but also for oneself. In interpersonal situations, Americans may tend to regret events that involved negative consequences for themselves. These findings suggest that the contents of regret reflect respective cultural values.

The Relation between Intensity and Types

Finally, we explored whether regret type was related to regret intensity. The means and standard deviations for intensity of each regret type are shown in Table 1. First, we regressed intensity in each situation on Type (inaction $=0$ and action $=1$ ). Regret type did not predict intensity in either interpersonal or self situations, $\beta=0.13, p=.13, R^{2}=.009$ or $\beta=0.10, p=.23$, $R^{2}=.001$, respectively. Second, we examined whether regret type mediated cultural differences in intensity. We regressed intensity in interpersonal situations on Time (short term $=0$ and long term $=1$ ) and Culture (US = 0 and Japan =1). Results showed that both Time and Culture significantly predicted intensity, $\beta=0.33$ and $\beta=0.25$, respectively, $p s<.01, R^{2}=.17$. Next, we further entered Type (inaction $=0$ and action $=1$ ) as a predictor into the equation, and again found that 
whereas Time and Culture significantly predicted intensity, $\beta=0.32$ and $\beta=0.25$, respectively, $p s$ $<.01, R^{2}=.18$, Type did not, $\beta=0.09, p=.23$. This indicates that cultural differences in intensity are independent from the effect of type.

\section{Discussion}

In this research, we examined the cultural similarities and differences in regret, introducing the distinction between interpersonal and self situations. Consistent with our predictions, we found that Japanese participants experienced more regret than Americans in interpersonal situations. However, Americans felt as much regret as Japanese in self situations. These results support the contention that the degree to which people experience regret depends on both immediate contexts and cultural environments.

Furthermore, we also found situational and cultural effects on types of regret. The tendency to regret inaction over action was more pronounced in self situations than in interpersonal situations and was more pronounced among Americans than Japanese. Most notably, the tendency to regret inaction over action was reduced in interpersonal situations for Americans, and even reversed for Japanese participants. These results suggest that the distinction between interpersonal and self situations is important for understanding the cultural grounding of regret, both in terms of the intensity of regret and the types of regret (action vs. inaction).

Finally, we also found cultural similarities and differences in the content of regret. Consistent with previous studies (Gilovich \& Medvec, 1995), “failure to seize the moment” and 
“insufficient effort” were common regrets in self situations in both the U.S. and Japan, though Americans were more likely than Japanese to regret “failure to seize the moment”, which relates to the model of independent agency. In interpersonal situations, on the other hand, "hurting others" was the most common regret across cultures, although Japanese were more likely than Americans to regret it, possibly due to Japanese sensitivity to interpersonal consequences of actions.

The present research reasoned that a sense of agency and responsibility underlies cultural differences in the intensity of regret experienced in interpersonal situations. However, it is also possible that Japanese are more likely than Americans to care about ramifications of an event on other people, which may make Japanese have more intense experiences of not only regret but also all emotions in interpersonal situations. In fact, recent research on emotions has shown that East Asians are more likely than Americans are to have strong emotional experiences, especially positive ones, in interpersonal contexts (Chentsova-Dutton \& Tsai, 2010; Uchida, Townsend, Markus \& Bergsieker, 2009). However, Chentsova-Dutton and Tsai (2010) also found that this effect was smaller or even absent for negative emotions (i.e., sadness and disgust) in comparison to positive emotions. In contrast, the present study found clear cultural differences in regret. This discrepancy between the findings for regret and other negative emotions suggests the possibility that a sense of agency, which distinguishes regret from other negative emotions (van Dijk \& Zeelenberg, 2002), underlies cultural differences in the intensity of regret.

Although most of the results supported our predictions, some unexpected results were 
also obtained. First, we did not find cultural differences in the intensity of regret in self situations. Japanese felt as strong regret as Americans did. Some studies have shown that Japanese are more likely to engage in self-critical thinking than do Americans (Heine et al., 1999). It is possible that Japanese individuals may focus on their negative aspects more and hence feel more regret, even in situations that do not involve others. Second, contrary to the previous findings (Gilovich \& Medvec, 1994), we did not find the temporal pattern of regret over inactions and actions. A simple explanation was low statistical power due to small sample sizes. At the same time, individual differences in the tendency to recall inaction or action might have overridden the temporal pattern of regret (e.g., Feldman et al., 1998). It is noteworthy that, despite such individual differences, we still found the effect of self and interpersonal contexts.

The present findings suggest the possibility that regret functions to promote adaptation to one’s cultural context. Because people try to avoid strong regrets, anticipation of regret may motivate people to behave in ways consistent with their cultural norms. By demonstrating how characteristics of regret are grounded in cultural contexts, the present research indicates that regret may play an important role in maintaining and reinforcing cultural meaning systems. 


\section{References}

Berndsen, M., van der Pligt, J., Doosje, B., \& Manstead, A. S. R. (2004). Guilt and regret: The determining role of interpersonal and intrapersonal harm. Cognition and Emotion, 18, 55-70.

Chen, J., Chiu,C., Roese, N.J., Tam, K., \& Lau, I. Y. (2006) Culture and counterfactuals: On the importance of life domains. Journal of Cross-Cultural Psychology, 37, 75-84.

Chentsova-Dutton, Y. E. \& Tsai, J. L. (2010). Self-focused attention and emotional reactivity: The role of culture. Journal of Personality and Social Psychology, 98, 507-519.

Cooper, J., \& Fazio, R. H. (1984). A new look at dissonance theory. In L. Berkowitz (Ed.), Advances in experimental social psychology (Vol. 17, pp. 229-266). New York: Academic Press.

Feeney, A., Gardiner, D. R., Johnston, K., Jones, E., \& Mcevoy, R. J. (2005). Is regret for inaction relatively self-enhancing? Applied Cognitive Psychology, 19, 761-777.

Feldman, J., Miyamoto, J., \& Loftus, E. F. (1999). Are actions regretted more than inactions? Organizational Behavior and Human Decision Processes, 78, 232-255.

Gilovich, T., \& Medvec, V. H. (1994). The temporal profile to the experience of regret. Journal of Personality and Social Psychology, 67, 357-365.

Gilovich, T., \& Medvec, V. H. (1995). The experience of regret: What, when, and why. Psychological Review, 102, 379-395.

Gilovich,T., Wang, R. X., Regan, D.,\& Nishina, S. (2003). Regrets of action and inaction across 
cultures. Journal of Cross-Cultural Psychology, 34, 61-71.

Heine, S., \& Lehman, D. (1997). Culture, dissonance, and self-affirmation. Personality and Social Psychology Bulletin, 23(4), 389-400.

Heine, S. J., Lehman, D. R., Markus, H. \& Kitayama, S. (1999). Is there a universal need for positive self-regard? Psychological Review, 106, 766-794.

Iyengar, S. S. \& Lepper, M. R. (1999). Rethinking the role of choice: A cultural perspective on intrinsic motivation. Journal of Perosnality and Social Psychology, 76, 349-366.

Kahneman, D., \& Tversky, A. (1982). The psychology of preferences. Scientific American, 246, 160-173.

Kitayama, S., Snibbe, A., Markus, H., \& Suzuki, T. (2004). Is There Any 'Free' Choice?: Self and Dissonance in Two Cultures. Psychological Science, 15, 527-533.

Lee, A. Y., Aaker, J. L. \& Gardner, W. L. (2000). The pleasures and pains of distinct self-construals: The role of interdependence in regulatory focus. Journal of Personality and Social Psychology, 78, 1122-1134.

Markus, H. R., \& Kitayama, S. (2004). Models of agency: Sociocultural diversity in the construction of action. In V. Murphy-Berman \& J. Berman (Eds.), The 49th annual Nebraska Symposium on Motivation: Cross-cultural differences in perspectives on self (pp. 1-57). Lincoln: University of Nebraska Press.

Miller, J. G. (2004). Culture and agency: Implications for psychological theories of motivation and 
social development. In V. Murphy-Berman \& J. Berman (Eds.), The 49th annual Nebraska Symposium on Motivation: Cross-cultural differences in perspectives on self (pp. 59-99). Lincoln: University of Nebraska Press.

Pierro, A., Leder, S., Mannetti, L., Higgins, E. T., Kruglanski, A. W. \& Antonio, A. (2008).

Regulatory mode effects on counterfactual thinking and regret. Journal of Experimental Social Psychology, 44, 321-329.

Uchida, Y., Townsend, S. S. M., Markus, H. R., \& Bergsieker, H. B. (2009). Emotions as within or between people?: Cultural variation in lay theories of emotion expression and inference. Personality and Social Psychology Bulletin, 35,1427-1439.

Roese, N. J. , Hur, T. \& Pennington, G. L. (1999). Counterfactual thinking and regulatory focus: Implications for action versus inaction and sufficiency versus necessity. Journal of Personality and Social Psychology, 77, 1109-1120.

Ryan, R. M. (1991). The nature of self in autonomy and relatedness. In J. Strauss \& G. R. Goethals (Eds.), The self: Interdisciplinary approaches. New York: Springer.

Van Dijk, E. \& Zeelenberg, M. (2002). Invetsigating the appraisal patterns of regret and disappointment. Motivation and Emotion, 26, 321-331.

Zeelenberg, M., Pligt, J. van der, \& Manstead, A.S.R. (1998). Undoing regret on Dutch television: Apologizing for interpersonal regrets involving actions and inactions. Personality and Social Psychology Bulletin, 24, 1114-1120. 
Zeelenberg, M., \& Pieters, R. (2006). Looking backward with an eye on the future. In L. J. Sanna, \& E. C. Chang (Eds.), Judgments over time: The interplay of thoughts, feelings, and behaviors (pp.210-229). Oxford, UK: Oxford University Press.

Zou, X., Tam, K., Morris, M., Lee, S., Lau, I., \& Chiu, C. (2009). Culture as common sense: Perceived consensus versus personal beliefs as mechanisms of cultural influence. Journal of Personality and Social Psychology, 97, 579-597. 


\section{Footnotes}

${ }^{1}$ We examined both short-term and long-term regrets because previous research suggested that the tendency to regret inactions over actions is stronger for long-term regrets than for short-term regrets (Gilovich \& Medvec, 1995), although some did not find this temporal pattern (Feldman, Miyamoto, \& Loftus, 1999).

${ }^{2}$ Four participants (three Japanese and one American) who completed only half of the questionnaire were excluded from the analyses.

${ }^{3}$ We excluded four events (two by Japanese and two by Americans) which could not be considered as regrets based on the content coding (e.g., "If only he had learned from previous arguments, then we would not have fought.”). Including them, there were three Japanese and four Americans who were missing one of four regrettable events. Due to these missing cases, an ANOVA was run with 26 Japanese and 21 Americans who reported regret in all four situations. 
Culture and Regret 24

\section{Figure Caption}

Figure 1. The means and standard errors of intensity of regret in interpersonal and self situations in

Japan and the United States. 


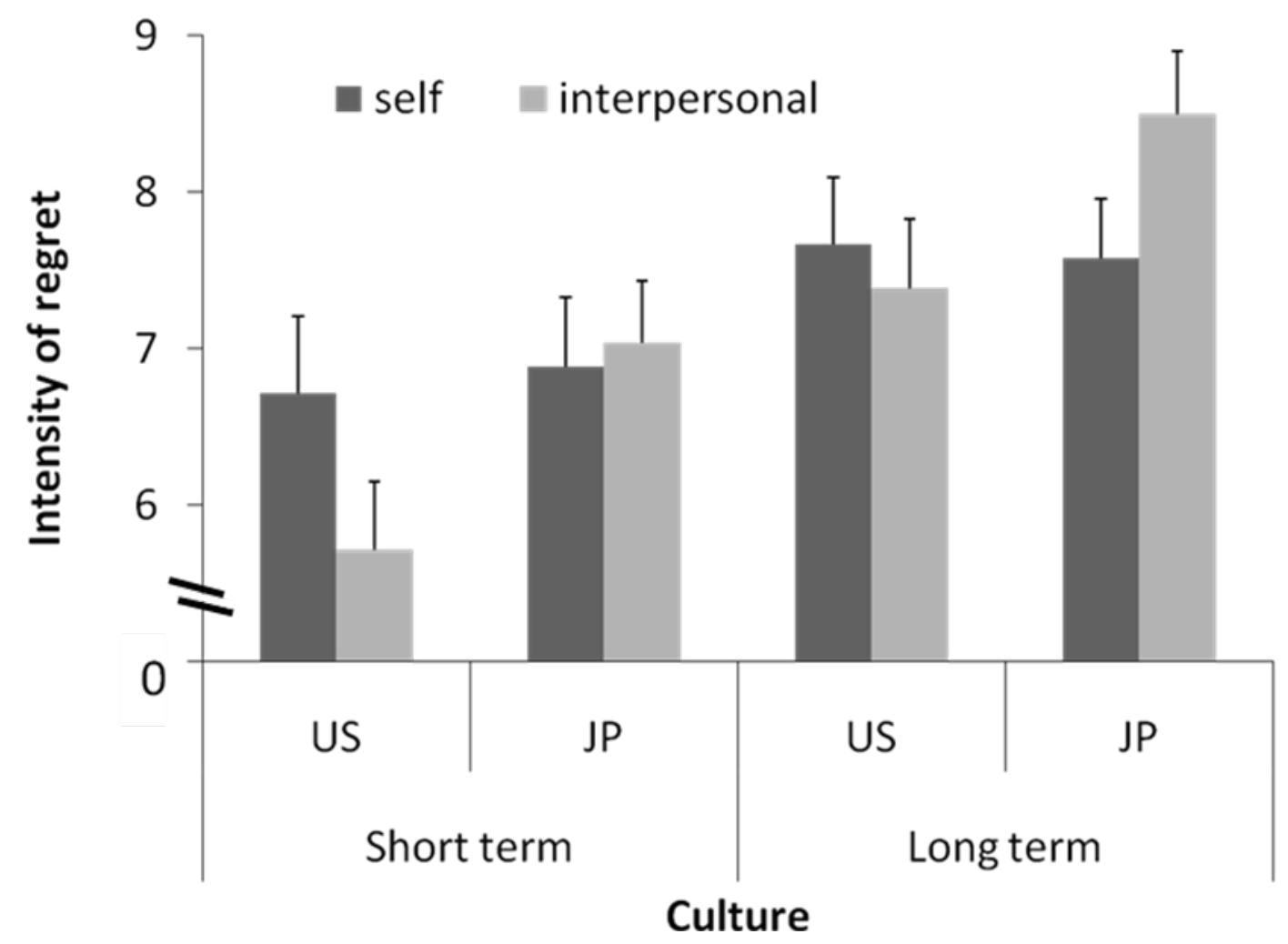


CULTURE AND REGRET 26

Table1. Frequency and intensity of common regrets in daily life for American and Japanese students

\begin{tabular}{|c|c|c|c|c|c|c|c|}
\hline \multicolumn{8}{|c|}{ Self situation } \\
\hline Inaction & & US & JP & Action & & US & JP \\
\hline \multirow{3}{*}{$\begin{array}{l}\text { 1. Failure to seize the moment } \\
\text { / not working enough. }\end{array}$} & $n$ & 48 & $32 *$ & \multirow{3}{*}{$\begin{array}{l}\text { 1. Unwise decisions giving up } \\
\mathrm{X} \text { / too much committing } \mathrm{X} \text {. }\end{array}$} & $n$ & 4 & $10+$ \\
\hline & $M$ & 7.50 & 7.16 & & $M$ & 8.25 & 7.90 \\
\hline & $S D$ & 1.74 & 2.07 & & $S D$ & 2.36 & 1.91 \\
\hline \multirow{6}{*}{$\begin{array}{l}\text { 2. Not caring enough about } \\
\text { health. }\end{array}$} & $n$ & 2 & 2 & \multirow{3}{*}{ 2. Wasting time on $\mathrm{X}$. } & $n$ & 1 & $8 *$ \\
\hline & $M$ & 3.50 & 3.50 & & $M$ & 9.00 & 7.00 \\
\hline & $S D$ & 3.54 & 2.12 & & $S D$ & - & 1.69 \\
\hline & & & & \multirow{3}{*}{$\begin{array}{l}\text { 3. Impulsive actions damaging } \\
\text { health/diet. }\end{array}$} & $n$ & 1 & 4 \\
\hline & & & & & $M$ & 6.00 & 7.75 \\
\hline & & & & & $S D$ & - & 1.71 \\
\hline \multirow{3}{*}{ 3. Miscellaneous inaction } & $n$ & 3 & 4 & \multirow{3}{*}{ 4. Miscellaneous action } & $n$ & 3 & 1 \\
\hline & $M$ & 6.67 & 8.50 & & $M$ & 7.00 & 10.00 \\
\hline & $S D$ & 2.52 & 1.73 & & $S D$ & 1.00 & - \\
\hline \multirow[t]{3}{*}{ Total } & $n$ & 53 & $38 *$ & \multirow[t]{3}{*}{ Total } & $n$ & 9 & $23 *$ \\
\hline & $M$ & 7.30 & 7.11 & & $M$ & 7.67 & 7.65 \\
\hline & $S D$ & 1.96 & 2.20 & & $S D$ & 1.80 & 1.80 \\
\hline
\end{tabular}

Interpersonal situation

\begin{tabular}{|c|c|c|c|c|c|c|c|}
\hline Inaction & & US & JP & Action & & US & JP \\
\hline \multirow{3}{*}{$\begin{array}{l}\text { 1. Not giving help to friends } \\
\text { and relatives. }\end{array}$} & $n$ & 6 & 6 & \multirow{3}{*}{$\begin{array}{l}\text { 1. Hurting or annoying friends } \\
\text { and relatives. }\end{array}$} & $n$ & 17 & $29 *$ \\
\hline & $M$ & 5.33 & 8.33 & & $M$ & 7.53 & 7.97 \\
\hline & $S D$ & 2.07 & 1.63 & & $S D$ & 1.59 & 1.82 \\
\hline \multirow{3}{*}{$\begin{array}{l}\text { 2. Not spending enough time } \\
\text { with friends and relatives. }\end{array}$} & $n$ & 8 & 4 & \multirow{3}{*}{$\begin{array}{l}\text { 2. Giving priority to some } \\
\text { relationships instead of } \mathrm{X} \text {. }\end{array}$} & $n$ & 2 & 4 \\
\hline & $M$ & 7.75 & 9.50 & & $M$ & 6.00 & 8.25 \\
\hline & $S D$ & 1.91 & 1.00 & & $S D$ & 1.41 & 1.50 \\
\hline \multirow{3}{*}{$\begin{array}{l}\text { 3. Missed opportunity to } \\
\text { form /maintain relationships. }\end{array}$} & $n$ & 10 & 8 & \multirow{3}{*}{$\begin{array}{l}\text { 3. Behaviors causing the break } \\
\text { up of relationships. }\end{array}$} & $n$ & 7 & 7 \\
\hline & $M$ & 7.00 & 7.00 & & $M$ & 8.14 & 8.71 \\
\hline & $S D$ & 2.36 & 2.45 & & $S D$ & 1.57 & 1.11 \\
\hline \multirow{3}{*}{$\begin{array}{l}\text { 4. Poor group performance } \\
\text { because of inaction. }\end{array}$} & $n$ & 6 & $1+$ & \multirow{3}{*}{$\begin{array}{l}\text { 4. Poor group performance } \\
\text { because of action. }\end{array}$} & $n$ & 5 & \\
\hline & $M$ & 6.00 & 10.00 & & $M$ & 7.40 & 9.00 \\
\hline & $S D$ & 2.68 & - & & $S D$ & 2.41 & - \\
\hline \multirow{3}{*}{ 5. Miscellaneous inaction } & $n$ & 5 & 4 & \multirow{3}{*}{ 5. Miscellaneous action } & $n$ & 7 & 8 \\
\hline & $M$ & 6.60 & 7.25 & & $M$ & 5.86 & 7.75 \\
\hline & $S D$ & 2.22 & 0.96 & & $S D$ & 3.29 & 2.61 \\
\hline \multirow[t]{3}{*}{ Total } & $n$ & 35 & $23 *$ & \multirow[t]{3}{*}{ Total } & $n$ & 38 & $49 *$ \\
\hline & $M$ & 6.66 & 7.96 & & $M$ & 7.24 & 8.08 \\
\hline & $S D$ & 2.22 & 1.97 & & $S D$ & 2.14 & 1.82 \\
\hline
\end{tabular}

Note: $* p<.05,+p<.10$ 